\title{
Endocardite infecciosa - uma suspeita sempre presente
}

Ana Santos Ferreira*

\section{RESUMO}

Introdução: O diagnóstico de endocardite infecciosa requer um elevado grau de suspeição para ser estabelecido atempadamente. O médico de família, conhecendo os fatores de risco de cada doente, está numa posição privilegiada para a suspeita clínica de endocardite, podendo desempenhar um papel fulcral no diagnóstico desta patologia.

Descrição do Caso: Manuel, utente de 59 anos acompanhado na nossa consulta desde 2007, tem como antecedentes pessoais 3 episódios prévios de endocardite infecciosa, dois dos quais associados a prótese valvular colocada na sequência do primeiro episódio. Foi acompanhado na nossa consulta por um quadro de síndrome febril indeterminado, associado a parâmetros inflamatórios elevados, com dois ecocardiogramas negativos realizados a nível hospitalar. Por se tratar de um utente de risco elevado para recorrência de endocardite infecciosa, a médica de família nunca abandonou esta hipótese diagnóstica. Perante o quadro, pediu hemoculturas em ambulatório, que foram positivas para Enterococos faecalis. O doente foi novamente enviado ao hospital, desta vez realizando um ecocardiograma que revelou vegetação, tendo-se estabelecido o diagnóstico definitivo de endocardite infecciosa 20 dias após o início do quadro clínico. Foi internado e cumpriu antibioterapia. Contudo, no início do segundo mês de internamento, teve um episódio de AVC hemorrágico, tendo como consequências hemiparesia direita e disartria a longo prazo.

Comentário: Apesar de se tratar de uma doença rara, a endocardite infecciosa associada a próteses valvulares está associada a elevada morbimortalidade. A forma de apresentação é variável, estando o médico dependente de um elevado grau de suspeição para conseguir estabelecer o diagnóstico atempadamente, minimizando as sequelas a longo prazo. Os critérios de Duke facilitam o estabelecimento adequado do diagnóstico; no entanto a sensibilidade destes critérios diminui em doentes com próteses valvulares. Trata-se de um quadro subagudo de endocardite, necessitando de 20 dias para se estabelecer o diagnóstico final, após o resultado de hemoculturas positivas. Foi a persistência da suspeita diagnóstica que permitiu o diagnóstico atempado.

\section{INTRODUÇÃO}

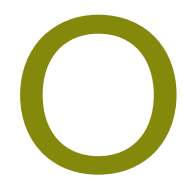

diagnóstico de endocardite infecciosa requer um elevado grau de suspeição para ser estabelecido, quer pela inexistência de sintomas suficientemente específicos que sirvam de alerta, quer pelo carácter insidioso com que a doença pode decorrer, apesar da sua gravidade. $\mathrm{O}$ diagnóstico atempado melhora o prognóstico dos doentes, minimizando as suas complicações, que incluem: 1) complicações cardíacas (insuficiência cardíaca, abcesso cardíaco, arritmia); 2) episódios trombóticos (enfarte agudo do miocárdio, acidente vascular cerebral, tromboembolismo pulmonar);3) infeções de outros órgãos (meningite, pneumonia, osteomielite); 4) complicações a nível de outros órgãos (insufi-

*Interna de Medicina Geral e Familiar, $36^{\circ}$ curso, USF Cova da Piedade ciência renal, abcessos). ${ }^{1,2}$ A mortalidade intra-hospitalar da endocardite infecciosa varia entre 10 e $26 \%{ }^{1}$

Apesar da gravidade da endocardite infecciosa, a inserção desta patologia no diagnóstico diferencial dos quadros febris habituais é dificultada pela sua raridade. De facto, trata-se de uma doença com baixa incidência (3-10 episódios/ 100.000 doentes/ano). ${ }^{1}$ No entanto, importa estabelecer o diagnóstico o mais precocemente possível pelas razões já apontadas. Neste sentido, o médico de família encontra-se numa posição privilegiada para a suspeita atempada desta patologia, uma vez que conhece o doente e a sua história clínica prévia, incluindo os seus fatores de risco, e tem a possibilidade de acompanhar de perto a evolução do quadro clínico. Nesta perspetiva, o médico de família pode desempenhar um papel fulcral no diagnóstico desta patologia, tão bem ilustrado no caso que se apresenta. 
Este caso ilustra também a dificuldade no processo diagnóstico de uma endocardite, e do seu diagnóstico diferencial num quadro de febre arrastada.

\section{DESCRIÇÃO DO CASO}

\section{Identificação}

Manuel (nome fictício) é um utente caucasiano, tem 59 anos de idade, é natural e residente no distrito de Setúbal. Tem o $4^{\circ}$ ano de escolaridade e é preparador de trabalho num estaleiro naval. É casado e tem dois filhos. A família pertence à classe III de Grafar. Trata-se de uma família nuclear, na fase VII do Ciclo de Duvall. A Figura 1 revela o genograma familiar com a representação da psicofigura de Mitchel do agregado familiar.

\section{Antecedentes Pessoais}

Manuel é seguido na nossa consulta desde 2007; os dados prévios a esta data são escassos. Dos antecedentes pessoais, destaca-se um primeiro episódio de endocardite infecciosa em 1998 em contexto de periodontite (sem outro fator de risco), com necessidade de colocação de prótese valvular aórtica biológica. Em 2002 teve um novo episódio de endocardite infecciosa da prótese, que resultou na substituição desta por uma prótese mecânica. Um ano depois, teve novo episódio de endocardite aguda, desta vez sem necessidade de cirurgia. Apesar de aconselhado, não realizou tratamento orientado de periodontite. É seguido em consulta de cardiologia no hospital da área de residência. Está anticoagulado com varfarina, com valores de International Normalized Ratio (INR) irregulares, alternando entre níveis subterapêuticos e níveis acima do intervalo

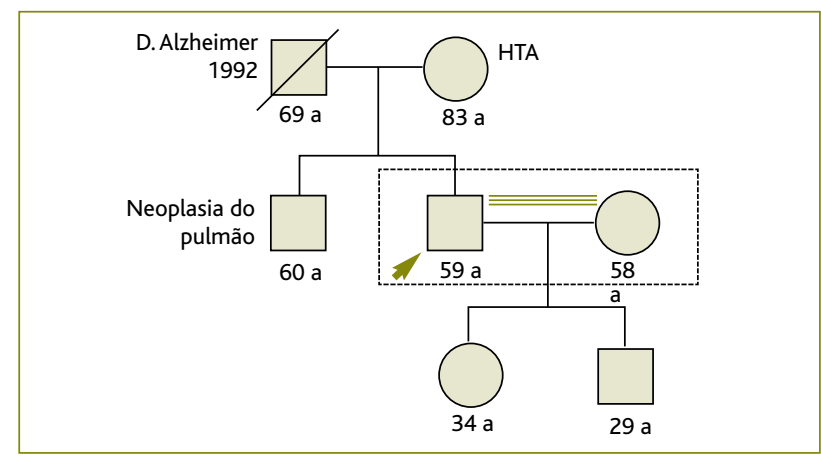

Figura 1. Genograma Familiar com representação de psicofigura de Mitchell. terapêutico, por má adesão a toma dos fármacos e a vigilância laboratorial. O último ecocardiograma, realizado no início de 2006, revelava cavidades não dilatadas ou hipertrofiadas, com função sistólica preservada.

Manuel apresenta ainda como antecedentes pessoais dislipidémia, hipertensão sem complicações, litíase renal com cólicas renais de repetição (última cólica em 2003), úlcera péptica em 1985 (entretanto cicatrizada), hiperplasia benigna da próstata e hiperuricemia. Manteve hábitos tabágicos até 1998 (20 cigarros/dia), e tem hábitos alcoólicos moderados.

Medicado cronicamente com sinvastatina $20 \mathrm{mg}$ por dia, ramipril $10 \mathrm{mg}$ por dia, e varfarina.

\section{História de Doença Atual}

A história da doença atual iniciou-se quando Manuel recorreu à consulta em setembro de 2007 por um quadro com 5 dias de evolução de febre vespertina (temperatura axilar de $37,5^{\circ} \mathrm{C}$ a $38^{\circ} \mathrm{C}$ ), associada a uma discreta odinofagia, sem outros sintomas. Do exame objetivo, destacava-se um sopro sistólico audível no foco aórtico, já previamente conhecido. A inspeção da cavidade oral revelou a presença de periodontite, sem outras alterações da orofaringe. O restante exame objetivo não revelava alterações. Neste contexto, e dados os antecedentes do doente, foram pedidos parâmetros inflamatórios e INR urgentes. Tinha programada a realização de ecocardiograma de rotina no hospital dentro de um mês.

Quatro dias depois, regressou à consulta para mostrar os resultados das análises pedidas, mantendo as mesmas queixas. Analiticamente, apresentava anemia normocítica normocrómica (Hb 10,6 g/dL), proteína C-reactiva (PCR) de 9,46 g/dL e velocidade de sedimentação (VS) de $50 \mathrm{~mm} /$ hora. O INR nesta altura era de 2,4. Tratava-se assim de um síndrome febril com elevação dos parâmetros inflamatórios, de etiologia a esclarecer. Devido aos antecedentes pessoais, colocou-se a hipótese de se tratar de um episódio recorrente de endocardite infecciosa aguda, motivo pelo qual se procedeu à referenciação ao serviço de urgência hospitalar. Já no hospital, foram realizadas análises sanguíneas e foi efetuado um ecocardiograma transtorácico que não revelou alterações, e Manuel teve alta clínica, sem pedido de hemoculturas, com indicação para manter vigilância junto do médico assistente. 
Passados três dias, Manuel voltou à nossa consulta por manutenção das queixas, agora também com diminuição do apetite. Ao exame objetivo apresentava a orofaringe hiperemiada, mantendo-se o sopro sistólico com as mesmas características e a periodontite, sem outras alterações. Mantendo-se a suspeita de endocardite aguda, mas não descartando outros diagnósticos diferenciais para o quadro febril, foram pedidas serologias (Vírus de Imunodeficiência Humana (VIH) 1 e 2, Citomegalovirus e Vírus Epstein-Barr) e hemoculturas pelo médico de família, em ambulatório. Contactou-se o serviço de cardiologia do hospital, tendo-se conseguido antecipar a realização do ecocardiograma transesofágico já agendado, programando-se a sua realização dentro de cinco dias. Ficou programada a realização de prova de Mantoux, caso se verificasse persistência de sintomatologia.

Na data de realização do ecocardiograma, mantinha as queixas. O ecocardiograma revelou «Prótese mecânica em posição aórtica, sem imagem de vegetação, com insuficiência ligeira. Aneurisma periprotésico, fluxo sistólico com alterações ligeiras. Comunicação interventricular ao nível do septo intraventricular membranoso, sem imagem sugestiva de vegetação. Restantes estruturas valvulares sem vegetações ou outras alterações. Sem massas ou trombos visíveis. Ventrículo esquerdo com função sistólica conservada, não dilatado. Aorta torácica sem alterações significativas.»

Contudo, três dias depois da realização do ecocardiograma (20 dias após o início do quadro), Manuel estabeleceu um contacto telefónico para informar o resultado das hemoculturas. Estas tinham sido positivas para Enterococos faecalis, a favor de se tratar efetivamente de um novo episódio de endocardite aguda. As serologias foram negativas. Perante a septicémia confirmada, fez-se a referenciação para internamento no hospital, via serviço de urgência.

Manuel foi internado nesse mesmo dia, tendo realizado ecocardiograma transesofágico à entrada do serviço de internamento, que revelou uma imagem sugestiva de vegetação na prótese mecânica aórtica. Cumpriu um esquema de antibioterapia dirigida com vancomicina e gentamicina, que manteve durante um mês. Ao longo do internamento, verificou-se uma melhoria progressiva do quadro, ficando apirético 48 horas após início da antibioterapia. Verificou-se uma descida pro- gressiva dos parâmetros infecciosos (verificou-se uma descida da PCR de 2,6 mg/dL inicialmente para 1,8 $\mathrm{mg} / \mathrm{dL}$ ao $6^{\circ}$ dia de antibioterapia), mantendo-se o INR de difícil controlo. Em novo ecocardiograma transesofágico realizado 13 dias após o início de antibioterapia, já não apresentava a imagem de vegetação, revelando no entanto possível fístula da raiz da aorta para a aurícula direita, com shunt mínimo.

Ao $38^{\circ}$ dia de internamento, Manuel desenvolveu um quadro súbito de afasia e hemiparesia direita. Foi efetuada tomografia computorizada crânio-encefálica (TC-CE), que revelou «hematoma lenticular esquerdo (50x25mm), com ligeiro edema perilesional e compressão do ventrículo homolateral; sequelas vasculares isquémicas na substância branca; discreto desvio direito das estruturas da linha média». Fez-se assim o diagnóstico de acidente vascular cerebral (AVC) hemorrágico. Iniciou programa de reabilitação em regime de internamento.

Teve alta 8 semanas depois, após 13 semanas de internamento, mantendo hemiparesia direita e disartria, com instalação de sintomatologia depressiva. O INR manteve-se de difícil ajuste. Teve indicação para fazer dieta pobre em gorduras, polifracionada, bem como manutenção de abstinência tabágica e alcoólica. Foi referenciado: a consulta com o médico de família, para controlo de fatores de risco; a consulta de medicina física e de reabilitação, para manutenção do programa de reabilitação em ambulatório; a consulta de doenças vasculares cerebrais; a consulta de anticoagulação; e manteve seguimento em consulta de cardiologia. Foi medicado com lisinopril $5 \mathrm{mg}$ por dia, sinvastatina 20 mg por dia, sertralina $50 \mathrm{mg}$ por dia, varfarina $10 \mathrm{mg}$ por dia, fazendo enoxaparina sódica $100 \mathrm{mg} / \mathrm{ml}$ até ser atingido INR terapêutico. Iniciou tratamentos dentários em médico dentista particular.

Regressou à nossa consulta cerca de 1 mês após a alta hospitalar, mantendo ligeira hemiparesia direita com força muscular grau 3 e discurso não fluente, com raras parafasias, sequelares, pelo que passou a uma situação de reforma. Mantinha ainda sintomatologia depressiva importante, pelo que se aumentou dosagem de sertralina e se manteve contato regular com a família no sentido de otimizar o apoio ao utente, dispondo este de uma rede social importante de amigos e familia.

Atualmente, Manuel tem 64 anos, mantém hemipa- 
resia direita que tem vindo a melhorar com a fisioterapia, bem como disartria, apesar de ter feito terapia da fala. A dislipidémia e a hipertensão estão controladas (colesterol total $169 \mathrm{mg} / \mathrm{dL}$, colesterol HDL $48 \mathrm{mg} / \mathrm{dL}$, colesterol LDL 100,8 mg/dL, triglicéridos $101 \mathrm{mg} / \mathrm{dL}$, com valores de pressão arterial inferiores a 135/85 mmHg). O INR mantém-se estável em valores terapêuticos (entre 2,5 e 3,5), com controlo regular na consulta de anticoagulação hospitalar e boa adesão por parte do utente. Mantém vigilância em consulta de cardiologia, onde vai com uma periodicidade anual. Faz vacina da gripe anualmente e pneumo- 23 a cada 5 anos. Encontra-se medicado com varfarina $10 \mathrm{mg}$ por dia, lisinopril $5 \mathrm{mg}$ por dia, sinvastatina $20 \mathrm{mg}$ por dia e sertralina $100 \mathrm{mg}$ por dia.

\section{COMENTÁRIO}

A endocardite infecciosa é uma doença rara, com uma incidência de 3-10 episódios/100.000 pessoas-ano. ${ }^{1}$ Apesar do desenvolvimento dos exames complementares que auxiliam o seu diagnóstico e das abordagens terapêuticas, mantém uma elevada morbimortalidade. ${ }^{2}$ Dentro das endocardites infecciosas, a associada a próteses valvulares (quer mecânicas que biológicas) é a forma mais grave da doença. ${ }^{1}$

No caso clínico descrito, Manuel apresentou um quadro insidioso de febre baixa associado a sintomas inespecíficos, uma das formas de apresentação da endocardite. Estes sintomas inespecíficos podem confundir a avaliação inicial. De todos os sintomas, a febre é um dos sinais mais consistentes nos quadros de endocardite (está presente em até $90 \%$ dos doentes). ${ }^{1}$ Contudo, a endocardite pode também apresentar-se de forma aguda e de progressão rápida.

Dada a inexistência de um quadro clínico específico e atendendo à gravidade da doença, é imprescindível manter um elevado grau de suspeição para se fazer o diagnóstico atempado de endocardite. Contudo, perante um síndrome febril indeterminado, importa ter presente outros diagnósticos diferenciais, nomeadamente patologia infecciosa, neoplásica, autoimune e iatrogénica. ${ }^{3}$ No entanto, Manuel era um doente de elevado risco de recorrência de endocardite infecciosa, por ser portador de uma prótese valvular e pelos antecedentes de dois episódios prévios. ${ }^{1}$ Para além destes fatores de risco, existe um terceiro que não estava pre- sente em Manuel - a presença de doença cardíaca congénita. $O$ facto de a médica de família estar alerta para este elevado risco de recorrência de endocardite foi o ponto de partida para a colocação da doença no diagnóstico diferencial do quadro febril inespecífico.

Colocada a hipótese de endocardite, esta foi reforçada pela presença de sinais laboratoriais de infeção. De facto, analiticamente Manuel apresentava um aumento da PCR e daVS, anemia e leucocitose. Outro sinal que também pode estar presente é a presença de hematúria microscópica. Contudo, todos estes sinais laboratoriais têm baixa especificidade, e não integram os critérios diagnósticos actuais. ${ }^{1}$

De acordo com a Sociedade Europeia de Cardiologia, atualmente é reconhecida a importância da ecocardiografia, quer transtorácica quer transesofágica, no diagnóstico dos doentes com endocardite infecciosa (sendo também um exame útil na abordagem e seguimento destes doentes). Deve por isso ser realizada rapidamente, assim que haja suspeita de endocardite, preferencialmente o ecocardiograma transesofágico (devido à sua maior sensibilidade quando comparado ao ecocardiograma transtorácico: 90-100\% vs. 40-63\%). Existem três achados ecocardiográficos que são critérios major no diagnóstico de endocardite infecciosa vegetação, abcesso e deiscência da prótese valvular. Contudo, um ecocardiograma sem estas alterações não deve excluir o diagnóstico de endocardite num doente de risco. Isto pode dever-se a:

- Presença de lesões graves pré-existentes que mascaram a vegetação (prolapso da válvula mitral, lesões calcificadas degenerativas, próteses valvulares);

- Presença de uma vegetação com tamanho inferior a $2 \mathrm{~mm}$;

- Caso da vegetação ainda não se ter formado ou ter já embolizado;

- Endocardite não vegetante.

É ainda frequente um resultado falso negativo em casos de endocardite infecciosa associada a próteses valvulares, que era o caso de Manuel. Estes motivos podem justificar, no presente caso clínico, o resultado dos dois ecocardiogramas iniciais que foram pedidos ao longo da evolução do quadro, que não revelaram alterações de novo sugestivas de endocardite infecciosa. Contudo, sabendo de antemão que se trata de um exame não isento de falsos negativos e mantendo-se o elevado ní- 
vel de suspeita num doente de alto risco, um segundo ecocardiograma deve ser realizado 7-10 dias após um primeiro ecocardiograma negativo. ${ }^{1}$

A presença de hemoculturas positivas foi o ponto de viragem para o estabelecimento de um diagnóstico de endocardite infecciosa no caso de Manuel. As hemoculturas, para além de facilitarem o diagnóstico desta patologia, permitem ainda testar a sensibilidade antibiótica da bactéria encontrada. $\mathrm{O}$ facto de se tratar de uma patologia associada a bacteriemia persistente permite a colheita de hemoculturas fora do pico febril' ${ }^{1}$, tornando-se num exame relativamente cómodo de ser realizado.

Dada a dificuldade do diagnóstico de endocardite infecciosa, deve-se recorrer aos Critérios de Duke (Figura 2) para colocar o doente em uma de três categorias: diagnóstico definitivo, diagnóstico possível e diagnóstico improvável. ${ }^{1,2}$ Estes critérios baseiam-se em achados clínicos, ecocardiográficos e bacteriológicos. Quando corretamente aplicados, estes critérios têm uma elevada sensibilidade e especificidade (ambas cerca de $80 \%$ ) para o diagnóstico de endocardite infecciosa. No entanto, nos casos associados a próteses valvulares (como era o caso de Manuel), estes critérios apresentam uma sensibilidade inferior. ${ }^{1}$ Tratam-se assim de critérios úteis, mas que não devem substituir a impressão clínica.

No início do quadro de Manuel, de acordo com os critérios de Duke, não havia critérios para uma forte suspeita de endocardite infecciosa, pois estávamos na presença de apenas dois critérios minor - presença de prótese valvular e febre. Deste modo, apesar da suspeita, esta não era suficiente para a introdução de antibioterapia empírica, preconizada para casos de forte suspeita de endocardite infecciosa, enquanto se aguarda o resultado de hemoculturas, ou quando estas são negativas. ${ }^{1}$ Contudo, nesta altura não dispúnhamos de informação crucial para a correta aplicação dos critérios de Duke - resultados de hemoculturas e de ecocardiograma. Antes de ter sido internado, Manuel apresentava já um terceiro critério minor (hemocultura positiva para Enterococos faecalis) associado aos dois previamente presentes, colocando-o na categoria de diagnóstico possível. Só depois do internamento, após a realização do segundo ecocardiograma transesofágico, foi revelada a presença de vegetação (primeiro cri-

\section{Critérios Major}

Isolamento dos agentes típicos de El em duas hemoculturas distintas, sem foco primário: Streptococcus viridans, Streptococcus bovis, grupo HACEK, Staphylococcus aureus ou bateriémia por enterococo adquirido na comunidade.

Micro-organismo compatível com El isolado em hemoculturas persistentemente positivas.

Única cultura ou serologia positiva (IgG>1:800) para Coxiella burnetti.

Regurgitação valvular de novo (aparecimento de sopro ou alteração de sopro pré-existente não é suficiente).

Ecocardiograma com evidências de endocardite (existem 3 achados possíveis: massa intracardíaca oscilante ecogénica em local de lesão endocárdica, abcesso perivalvar e nova deiscência em válvula prostética).

\section{Critérios Minor}

Fator predisponente para El (uso de drogas injetáveis ou doença cardiovascular predisponente).

Febre $>38^{\circ} \mathrm{C}$.

Fenómenos vasculares (excepto petéquias e outras hemorragias).

Fenómenos imunológicos (presença de fator reumatóide, glomerulonefrite, nódulo de Osler ou manchas de Roth).

Hemocultura positiva que não preencha critérios major ou evidência serológica de infeção ativa (exclui-se hemocultura única positiva para estafilococo coagulase-negativo ou para micro-organismo que raramente cause endocardite).

Diagnóstico Possível: São necessários a presença 1 critério major e 1 critério minor OU 3 critérios minor.

Diagnóstico Definitivo: São necessários a presença de 2 critérios major OU 1 critério major e 3 critérios minor OU 5 critérios minor.

Figura 2. Critérios de Duke Modificados (adaptado de Baddour L. et al. $\left.{ }^{2}\right)$

tério major). Este novo dado permitiu estabelecer o diagnóstico definitivo. No caso de Manuel, este episódio de endocardite pode classificar-se em endocardite 
infecciosa de válvula protésica, tardia, ativa, adquirida na comunidade, por reinfeção. ${ }^{1}$

Apesar de ter sido detetada e de se ter iniciado a antibioterapia correta que permitisse a resolução da endocardite, Manuel veio a desenvolver, ainda no internamento, um AVC hemorrágico. Os eventos neurológicos são complicações frequentes da endocardite infecciosa, desenvolvendo-se em $20-40 \%$ destes doentes. Contudo, estes são sobretudo consequência de embolismo. No entanto, Manuel teve um AVC de origem hemorrágica, provável complicação secundária não da endocardite infecciosa em si, que na altura já estava resolvida, mas antes do difícil controlo do INR que apresentava. Também aqui o papel do médico de família é relevante: no acompanhamento do processo de reabilitação do utente após este evento e na promoção da adesão a um controlo eficaz da terapêutica anticoagulante no pós-internamento.

Tratando-se de um portador de uma válvula protésica com antecedentes pessoais de quatro episódios de endocardite infecciosa, o risco de reinfeção é elevado, ${ }^{1,4}$ devendo o médico assistente estar alerta para este facto. Neste âmbito, é importante capacitar o utente, levando-o a reconhecer a possibilidade de recorrência da doença e alertando-o para sinais e sintomas que devem motivar a procura de assistência médica. ${ }^{1}$ Relativamente à questão da prevenção de endocardite, tratando-se de um doente com risco muito elevado para endocardite infecciosa, justifica-se a profilaxia antibiótica nos procedimentos dentários de muito elevado risco (em tratamentos dentários que envolvam manipulação do tecido gengival, a região peri-apical dos dentes ou a perfuração da mucosa oral), de acordo com as orientações da American Heart Association, bem como da Sociedade Europeia de Cardiologia. No entanto, importa ressalvar que esta recomendação não é baseada em evidência, refletindo antes um consenso de opinião de peritos. ${ }^{5}$
Pretendeu-se com este caso chamar a atenção para a importância da manutenção da suspeição clínica em doentes de elevado risco para endocardite infecciosa apesar de exames negativos. Só a persistência da suspeição clínica permite melhorar o prognóstico da doença, uma vez que só assim é realizado um diagnóstico correto e atempado. Realça-se também a posição favorável do médico de família no seguimento destes doentes, através do conhecimento dos fatores de risco de cada doente e da manutenção de um contacto frequente que permite seguir de perto a evolução do quadro clínico.

\section{REFERÊNCIAS BIBLIOGRÁFICAS}

1. Habib G, Hoen B, Tornos P, Thuny F, Prendergast B, Vilacosta I, et al. Guidelines on the prevention, diagnosis, and treatment of infective endocarditis (new version 2009). Eur Heart J 2009 Oct; 30 (19): 2369413.

2. Baddour LM, Wilson WR, Bayer AS, Fowler VG Jr, Bolger AF, Levison ME, et al. Infective endocarditis: diagnosis, antimicrobial therapy, and management of complications: a statement for healthcare professionals. Circulation 2005 Jun 14; 111 (23): e394-e434.

3. Roth AR, Basello GM. Approach to the adult patient with fever of unknown origin. Am Fam Physician 2003 Dec 1; 68 (11): 2223-9.

4. Aurigemma G, Gaasch W. Management of patients with prosthetic heart valves. In: Basow O, editor. UpToDate. Waltham, MA: UpToDate; 2013.

5. European Society of Cardiology. ESC Essential Messages - ESC Guidelines on the prevention, diagnosis and treatment of infective endocarditis. Sophia Antipolis: European Society of Cardiology; 2010.

\section{CONFLITOS DE INTERESSE}

A autora declara não possuir conflitos de interesse.

\section{ENDEREÇO PARA CORRESPONDÊNCIA}

Ana Santos Ferreira

Av. Rainha D. Leonor, $\mathrm{n} .{ }^{\circ} 2-6 .^{\circ}$ e $7 .^{\circ}$ pisos,

2809-010 Almada

Email: anita.csf@gmail.com

Recebido em 16/10/2012

Aceite para publicação em 27/02/2013 


\section{ABSTRACT}

\section{INFECTIOUS ENDOCARDITIS - AN EVER-PRESENT SUSPICION}

Introduction: An elevated level of suspicion is required to make a timely diagnosis of infective endocarditis. The family physician with knowledge of the risk factors of each patient is in a privileged position to diagnose this disease.

Case Description: A 59 year-old male patient with a history of 3 previous episodes of infective endocarditis has been treated in our practice since 2007. Two episodes were associated with a prosthetic valve (a consequence of the first episode). He was seen recently for an episode of fever of unknown origin associated with high serum levels of markers of inflammation. Two echocardiograms performed in hospital were non-diagnostic. The family physician retained a suspicion of infective endocarditis in this high-risk patient. Ambulatory blood cultures were positive for Enterococcus faecalis. The patient was again sent to the hospital and the echocardiogram now revealed a cardiac vegetation, confirming the diagnosis of infective endocarditis, 20 days after the initial onset of symptoms. At the beginning of the second month of his stay at the hospital, the patient suffered a hemorrhagic stroke, leaving him with dysarthria and a right hemiparesis.

Discussion: Although infective endocarditis is a rare disease, it has high morbidity and mortality when associated with prosthetic heart valves. The presentation of the disease is variable, so the physician needs a high level of suspicion to make a prompt diagnosis and prevent long-term consequences. The Duke criteria may help with diagnosis. However, the sensitivity of the criteria is reduced in patients with prosthetic valves. This is a sub-acute case of endocarditis, in which the diagnosis was made with positive blood cultures after 20 days of symptoms. Persistent suspicion of endocarditis by the family doctor enabled a timely diagnosis.

Key words (MeSH): Endocarditis; Heart Valve Prosthesis; Fever of Unknown Origin. 